\title{
Renal function in preeclampsia
}

\author{
C. W. G. REDMAN, L. J. BEILIN, AND J. BONNAR \\ From the Department of the Regius Professor of Medicine and Nuffield Department of Obstetrics, Oxford
}

Preeclampsia (pregnancy-induced hypertension) is a disorder specific to pregnancy and the pathological changes it causes regress after delivery. Reversible hyperuricaemia is the most characteristic biochemical feature of preeclampsia, first noted nearly 60 years ago by Slemons and Bogert (1917). More recently, Chesley and Williams have shown that the high plasma urate is the result of renal tubular urate retention occurring independently of decreases in the glomerular filtration rate (GFR). Why renal tubular function should alter is not known but clinical and pathological studies clearly demonstrate that the degree of hyperuricaemia in preeclampsia reflects the severity of the disorder (Redman et al, 1976), as well as being the best correlate of renal biopsy changes (Pollak and Nettles, 1960).

Of the many possible causes of urate retention, lactate acidosis has received most attention. In non-pregnant subjecis, it explains the urate retention of starvation (Murphy and Shipman, 1963) and the hyperuricaemia following grand-mal convulsions (Warren et al, 1975). Previously it was thought that the hyperuricaemia of eclampsia was a consequence of convulsions; many investigators have shown that this is not so, and our own studies confirm that evidence of urate retention may be present weeks or months before there is any likelihood of eclamptic fits. It is possible that an ischaemic placenta may generate enough lactate to account for the changes, a view supported by the observations of Handler (1960) who showed a marked negative correlation between arterial lactate levels and urate clearance in preeclamptic and eclamptic women.

Circulatory changes in the kidney may provide an alternative explanation of urate retention. Angiotensin II is known to depress urate clearance without lowering GFR (Ferris and Gorden, 1968) although it is not thought to be the cause of the intense vasoconstriction of preeclampsia. The undiscovered factor, or factors, that causes preeclamptic vasospasm may exert an effect on renal tubular function similar to that of angiotensin II.

A falling GFR, and progressive uraemia, are late features of preeclampsia, usually associated with proteinuria. At this stage circulating fibrin degrada- tion products may appear (Bonnar et al, 1971), and the disease enters a final fulminating stage which, without intervention, ends either with eclampsia, a fetal death, or spontaneous labour and delivery. The poor fetal prognosis, once proteinuria develops, has been amply documented in the first British Perinatal Mortality Survey (Butler and Bonham, 1963). Preeclamptic uraemia is ischaemic in origin. Arterial constriction, glomerular endothelial swelling and intravascular fibrin deposition are all developed sufficiently to explain the deterioration in renal function.

One of the major problems in studying preeclampsia has been the lack of observations in the earliest stages of the disease. By managing selected high-risk patients in a combined antenatal hypertension clinic, we have been able to document the renal changes occurring throughout the evolution of preeclampsia.

\section{Methods and Results}

Chronic maternal hypertension is compatible with a perfectly normal pregnancy. If preeclampsia does not develop, the plasma urate is no different from that in

\begin{tabular}{|c|c|c|}
\hline \multirow{2}{*}{$\begin{array}{l}\text { Duration of } \\
\text { Pregnancy (weeks) }\end{array}$} & \multicolumn{2}{|c|}{ Mean Plasma Urate $(m g \% \pm 1 S D)$} \\
\hline & $\begin{array}{l}\text { Chronically } \\
\text { Hypertensive }\end{array}$ & Normotensive \\
\hline 16 & $\begin{array}{l}3.5 \pm 0.6 \\
(17)\end{array}$ & $\begin{array}{l}3.3 \pm 0.6 \\
(29)\end{array}$ \\
\hline 20 & $\begin{array}{l}3.6 \pm 0.8 \\
(35)\end{array}$ & $\begin{array}{l}3.44 \pm 0.6 \\
(36)\end{array}$ \\
\hline 24 & $\begin{array}{l}3.6 \pm 0.8 \\
(39)\end{array}$ & $\begin{array}{l}3.6 \pm 0.6 \\
(41)\end{array}$ \\
\hline 28 & $\begin{array}{l}3.6 \pm 0.7 \\
(39)\end{array}$ & $\begin{array}{l}3.7 \pm 0.7 \\
(41)\end{array}$ \\
\hline 32 & $\begin{array}{l}3.9 \pm 0.8 \\
(37)\end{array}$ & $\begin{array}{l}3.9 \pm 0.8 \\
(38)\end{array}$ \\
\hline 34 & $\begin{array}{l}4 \cdot 2 \pm 0.8 \\
(37)\end{array}$ & $\begin{array}{l}4.0 \pm 0.7 \\
(36)\end{array}$ \\
\hline 36 & $\begin{array}{l}4.4 \pm 0.9 \\
(38)\end{array}$ & $\begin{array}{l}4.4 \pm 0.8 \\
(41)\end{array}$ \\
\hline 38 & $\begin{array}{l}4 \cdot 8 \pm 1 \cdot 1 \\
(34)\end{array}$ & $\begin{array}{l}4.7 \pm 0.8 \\
(33)\end{array}$ \\
\hline After delivery & $\begin{array}{l}5 \cdot 2 \pm 1 \cdot 0^{1} \\
(39)\end{array}$ & $\begin{array}{l}4 \cdot 7 \pm 0 \cdot 8 \\
(39)\end{array}$ \\
\hline
\end{tabular}

Table I Plasma urate in pregnancy

Difference of the means: ${ }^{1} p<0.01$ 
normal pregnancy at any gestation (table I). The results are from $\mathbf{4 1}$ matched chronically hypertensive and normotensive individuals, followed serially throughout pregnancy. The hypertensive subjects were selected if the blood pressure exceeded 140/90 $\mathrm{mm} \mathrm{Hg}$ before 20 weeks' gestation. Excluded were those who later developed proteinuria or who were delivered of babies wieghing less than $2.5 \mathrm{~kg}$. Hyperuricaemia was not a reason for exclusion. Plasma urate was measured by the SMA $12 / 60$ colorimetric method with a coefficient of variation of $3 \%$. In both groups there is no change in plasma urate until 28 weeks. Thereafter begins a small but steady rise which accelerates towards term, when the levels approach the postnatal values. Postnatally, the expected difference in plasma urate between hypertensive and normotensive groups appears for the first time.

Whether or not the mother is initially chronically hypertensive, if preeclampsia supervenes the plasma urate rises well above these expected values. The figure shows an example. The patient's blood pressure began to rise at 28 weeks; her plasma urea first increased at 30 weeks; proteinuria appeared at 32 weeks, and she was delivered at 36 weeks. But the plasma urate increased at every visit after 14 weeks-a strikingly abnormal trend which allowed the diagnosis of preeclampsia to be made four weeks before the appearance of clinical signs.

The timing of the rise in plasma urate has been studied in 14 women whowere seen early in pregnancy studied serially thereafter and who all developed a

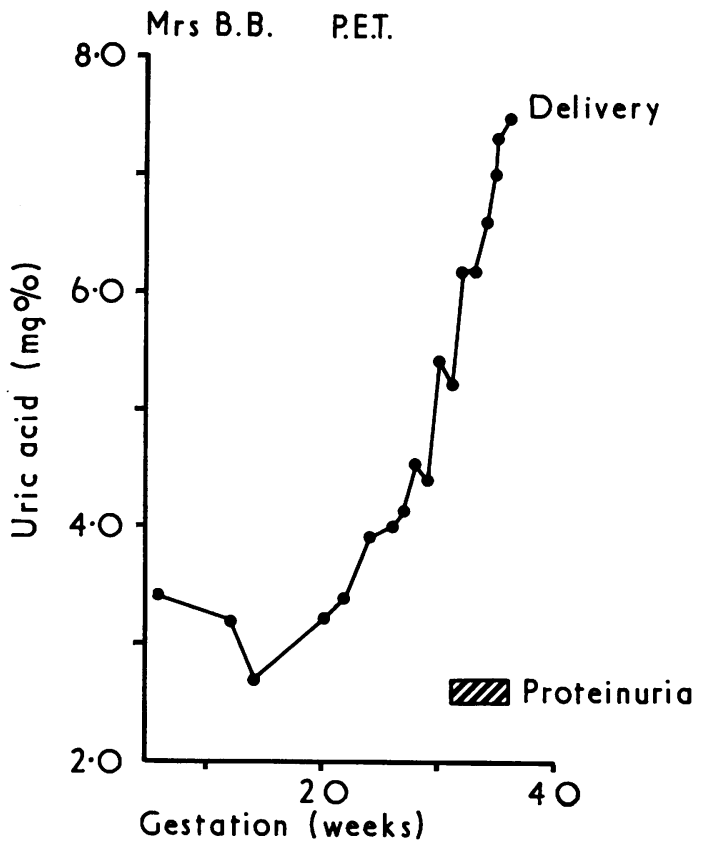

Fig Serial plasma urate levels in a pregnancy complicated by preeclampsia with proteinuria.

severe preeclampsia. The clinical details are shown in table II. The severity of the preeclampsia is indicated by the early gestation at delivery and the high perinatal mortality of $28.6 \%$ compared to our

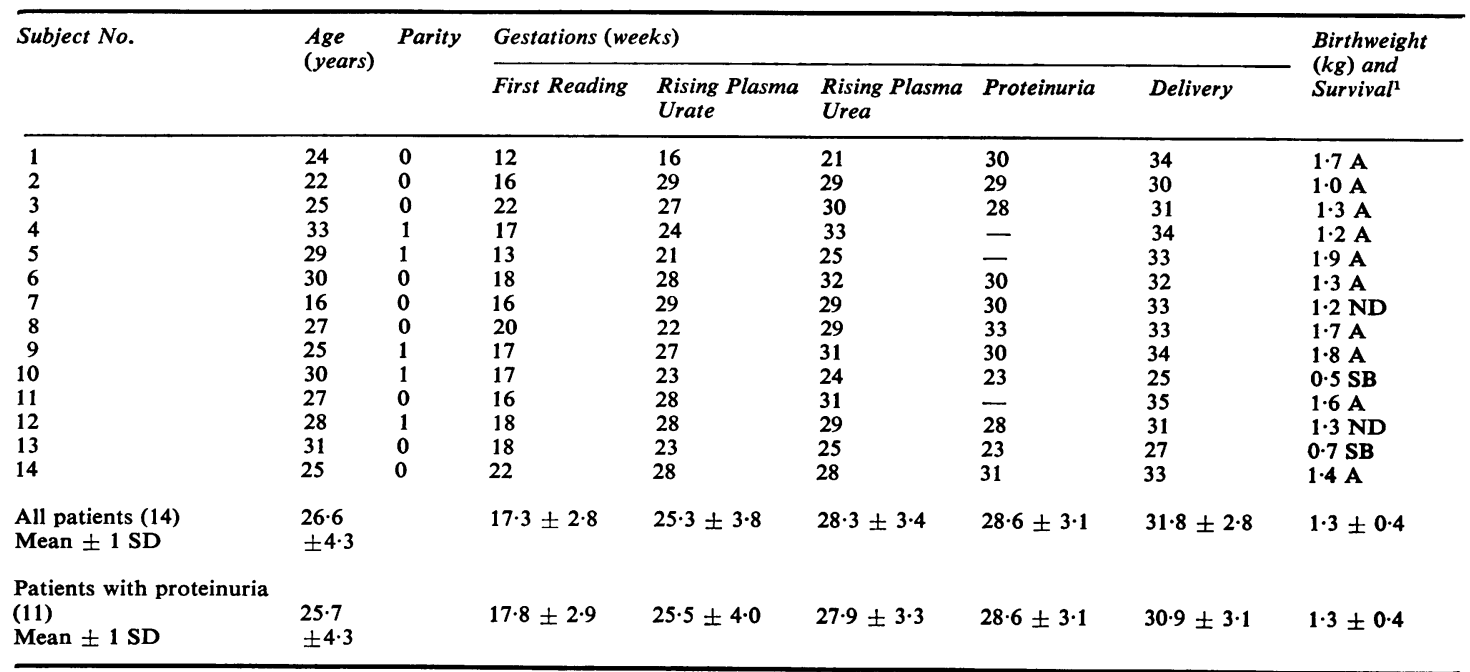

Table II Evolution of severe preeclampsia

${ }^{4}$ A: alive; SB: stillborn; ND: neonatal death 


\begin{tabular}{|c|c|c|c|c|c|}
\hline & \multirow{2}{*}{$\begin{array}{l}\text { Mean Value at } \\
\text { Assessment }\end{array}$} & \multicolumn{4}{|c|}{ Mean Change from Assessment Value } \\
\hline & & $\begin{array}{l}\text { At Time of Rising } \\
\text { Plasma Urate }\end{array}$ & $\begin{array}{l}\text { At Time of Rising } \\
\text { Plasma Urea }\end{array}$ & At Delivery & $\begin{array}{l}\text { Six Weeks after } \\
\text { Delivery }\end{array}$ \\
\hline $\begin{array}{l}\text { Uric acid }(\mathrm{mg} \%) \\
\text { Urea }(\mathrm{mg} \%) \\
\text { Platelets }\left(\mathrm{mm}^{-3}\right)\end{array}$ & $\begin{array}{l}4 \cdot 17 \pm 1 \cdot 16 \\
23 \cdot 9 \pm 6 \cdot 9 \\
212000 \pm 54000\end{array}$ & $\begin{array}{l}+0.95^{1} \\
+1 \cdot 0 \\
-17200\end{array}$ & $\begin{array}{l}+2 \cdot 11^{1} \\
+6 \cdot 7^{1} \\
-39200^{1}\end{array}$ & $\begin{array}{l}+4 \cdot 23^{1} \\
+18 \cdot 9^{1} \\
-63100^{1}\end{array}$ & $\begin{array}{l}+2 \cdot 17^{1} \\
+7 \cdot 9^{1} \\
+37000^{1}\end{array}$ \\
\hline
\end{tabular}

Table III Trends in renal function and platelet count with advancing preeclampsia

${ }^{1} \mathrm{P}<0.01$, paired rank sum test

hospital average of less than $1 \cdot 5 \%$. All these women were treated at some stage with antihypertensive agents but did not receive diuretics, which greatly alter the measurements of renal function. A rising plasma urate or urea was considered to be present if levels were consistently more than $2.0 \mathrm{mg} \%$ or 5 $\mathrm{mg} \%$ respectively above baseline levels. The gestation at which the rise began is shown in table II. In all patients, plasma urate began to increase either before or at the same time as the plasma urea increased. In one patient (no. 4) the two events were separated by as long as nine weeks. In three others (nos. 2, 7, 14) the two events coincided. Proteinuria did not develop in three patients and tended to appear at the same time or later than a rising plasma urate; but in no consistent time relation to the rise in plasma urea. On average a rising plasma urate preceded both proteinuria and a rising plasma urea by three weeks and a further three weeks then elapsed before delivery. Excluding the three patients without proteinuria, the average time course of the illness was slightly, but not significantly, shortened.

The starting values of plasma urea and urate taken at a mean gestation of 17 weeks were higher than average (tables I and III), reflecting the fact that in seven of the 14 patients renal abnormalities were diagnosed at that time or after birth. The trends in urea and urate are shown. At the time when plasma urate rose, the plasma urea had not significantly altered. Thereafter large and significant increases occurred in both values until delivery, with a subsequent fall six weeks after delivery.

Platelet counts taken at the same time have also been tabulated. The changes documented are of great interest. At the early development of a rising plasma urate, a trend to a falling platelet count is evident. This trend increases towards delivery and the change becomes highly significant. We do not have measurements of fibrin degradation products in all these women. It is our experience that an increase is a late feature of the disorder, but we have here clear-cut evidence that a falling platelet count is an early detectable event. This fall is occurring at a time when the platelet count is usually steady (table IV). These values are from our chronically

\begin{tabular}{ll}
\hline $\begin{array}{l}\text { Duration of } \\
\text { Pregnancy (weeks) }\end{array}$ & $\begin{array}{l}\text { Platelet Count }\left(\mathrm{mm}^{-3}\right) \pm 1 S D \text { and } \\
\text { No. of Observations }\end{array}$ \\
\hline 20 & $216000 \pm 60400(56)$ \\
24 & $223000 \pm 65500(77)$ \\
28 & $222000 \pm 61100(110)$ \\
32 & $216000 \pm 63900(114)$ \\
34 & $206000 \pm 61500(119)$ \\
36 & $201000 \pm 62500(121)$ \\
38 & $197000 \pm 61500(113)$ \\
six weeks after delivery $252000 \pm 68600(28)$
\end{tabular}

Table IV Platelet counts in hypertensive pregnant women

hypertensive patients, excluding those with severe preeclampsia. A small, very late fall in the average platelet count occurs, but there are no significant changes before 32 weeks.

\section{Discussion}

Our average values for plasma urate are higher than those reported by Boyle and colleagues (1966). These investigators deliberately stored their specimens for three weeks to allow the disappearance of non-urate chromogens-a procedure which we did not follow, and this probably explains the differences. Nonpregnant hypertensive individuals have a tendency to high plasma urate levels (Kinsey et al, 1961). It is interesting to see that these differences are obscured during pregnancy but appear six weeks after delivery.

Our observations confirm the impression that kidney involvement in preeclampsia takes place in two relatively clear-cut stages which develop with a highly variable time course. At one extreme the changes may be compressed into one or two weeks. At the other they may be spread out over two or three months. Hyperuricaemia is consistently the earliest change, with uraemia and proteinuria occurring later. The clinical relevance of these observations is that serial measurement of plasma urate may give considerable warning of developing preeclampsia, and the appearance of hyperuricaemia is highly correlated with impaired fetal prognosis (Redman et al, 1976).

Of great interest is the evidence that the platelet 
count is beginning to fall at the time that hyperuricaemia is developing. This is almost certainly an indicator of excessive platelet consumption, probably in the uteroplacental circulation. Preeclampsia is characterized by obstructive lesions in the uterine spiral arteries (Brosens, 1964), thought to be thrombotic in origin and in turn responsible for placental infarction. We may therefore be documenting events causing and resulting from progressive placental ischaemia, the platelet changes reflecting local spiral artery thrombosis and the hyperuricaemia either resulting from a lactate acidosis generated by the anoxic placenta or from changes in the renal circulation due to vasoactive substances released from the ischaemic placenta.

\section{References}

Bonnar, J., McNicol, G. P., and Douglas, A. S. (1971). Coagulation and fibrinolytic systems in pre-eclampsia and eclampsia. Brit. med. J., 2, 12-16.

Boyle, J. A., Campbell, S., Duncan, A. M., Greig, W. R., and Buchanan, W. W. (1966). Serum uric acid levels in normal pregnancy with observations on the renal excretion of urate in pregnancy. J. clin. Path., 19, 501-503.

Brosens, I. (1964). A study of the spiral arteries of the decidu basalis in normotensive and hypertensive pregnancies.
J. Obstet. Gynaec. Brit. Cwlth, 71, 222-230.

Butler, N. R., and Bonham, D. G. Eds. (1963). Perinatal Mortality: The First Report of the 1958 British Perinatal Mortality Survey. Livingstone, Edinburgh.

Chesley, L. C., and Williams, L. O. (1945). Renal glomerular and tubular function in relation to the hyperuricemia of pre-eclampsia and eclampsia. Amer. J. Obstet. Gynec., 50, 367-375.

Ferris, T. F., and Gorden, P. (1968). Effect of angiotensin and norepinephrine upon urate clearance in man. Amer.J. Med. 44, 359-365.

Handler, J. S. (1960). The role of lactic acid in the reduced excretion of uric acid in toxemia of pregnancy. J. clin. Invest., 39, 1526-1532.

Kinsey, D., Walther, R., Sise, H. S., Whitelaw, G., and Smithwick, R. (1961). Incidence of hyperuricemia in 400 hypertensive patients. (Abstr.) Circulation, 24, 972-973.

Murphy, R., and Shipman, K. H. (1963). Hyperuricemia during total fasting: renal factors. Arch. intern. Med., 112, 954-959.

Pollak, V. E., and Nettles, J. B. (1960). The kidney in toxemia of pregnancy: a clinical and pathologic study based on renal biopsies. Medicine (Baltimore), 39, 469-526.

Redman, C. W. G., Beilin, L. J., and Bonnar, J. (1976). The value of plasma urate measurements in predicting fetal death in hypertensive pregnancy. Lancet, in press.

Slemons, J. M., and Bogert, L. J. (1917). The uric acid content of maternal and fetal blood. J. biol. Chem., 32 , 63-69.

Warren, D. J., Leitch, A. G., and Leggett, R. J. E. (1975). Hyperuricaemic acute renal failure after epileptic seizures. Lancet, 2, 385-386. 